$1^{\text {st }}$ International Multidisciplinary Conference on Nutraceuticals and Functional Foods

Current Research in Nutrition and Food Science

Vol. 4(SI. 2), 114-118 (2016)

\title{
Antioxidant Properties of a Parsley (Petroselinum crispum) Juice Rich in Polyphenols and Nitrites
}

\section{CAMELIA PAPUC ${ }^{1}$, CORINA PREDESCU ${ }^{1 *}$, VALENTIN NICORESCU1, GEORGETA STEFAN ${ }^{2}$ and ISABELA NICORESCU ${ }^{3}$}

\author{
1Department of Preclinical Sciences, University of Agronomic Sciences \\ and Veterinary Medicine of Bucharest- 011464, Romania. \\ ${ }^{2}$ Department of Clinical Sciences, University of Agronomic Sciences and \\ Veterinary Medicine of Bucharest - 011464, Romania. \\ ${ }^{3}$ Department of Food Microbiology, Institute of Hygiene and Veterinary \\ Public Health, Bucharest - 021201, Romania.
}

http://dx.doi.org/10.12944/CRNFSJ.4.Special-Issue-October.15

(Received: August, 2016; Accepted: September, 2016)

\begin{abstract}
Parsley (Petroselinum crispum) is an herbaceous vegetable used as foodstuff, spice and medicinal plant because it provides antioxidants especially flavonoids (apigenin), vitamins ( $\mathrm{K}, \mathrm{C}$ and $\mathrm{A}$ ), and volatile oils, among other compounds. Because parsley has important concentrations of nitrates and flavonoids, very little vegetal pigment and a mild flavour profile, it was chosen for this study. The aim of this study was to obtain parsley juice rich in nitrite and polyphenols and to assess its antioxidant activity. To obtain nitrite from nitrate by enzymatic reaction, Staphylococcus xylosus ATCC 29971 was used as nitrate reductase source. To obtain the vegetable juice, fresh roots were minced and homogenized in aqueous solution. The sterile juice was filtered and then inoculated with $S$. xylosus and incubated at $37^{\circ} \mathrm{C}$. The nitrate and nitrite concentrations $(\mathrm{mg} / \mathrm{L})$ were determined using a colorimetric method using salicylic acid and Griess reagent, respectively. The total polyphenols content (TPC) was measured with Folin-Ciocalteu reagent and expressed as mg gallic acid equivalent / 100 $\mathrm{mL}$ (mg GAE / $100 \mathrm{~mL}$ ). The total flavonoids content (TFC) was measured with aluminium chloride reagent, and expressed as $\mathrm{mg}$ catechin equivalent / $100 \mathrm{~mL}$ (mg CE / $100 \mathrm{~mL}$ ). To determine the antioxidant activity of parsley juice, the ability to reduce DPPH synthetic radical, reducing power of $\mathrm{Fe}^{3+}$ ion and the capacity of chelating transition metal ions were assessed. Maximum concentration of nitrites was achieved for parsley juice in the presence of $S$. xylosus after 24 hours; TPC was 14.87 $\mathrm{mg} \mathrm{GAE} / 100 \mathrm{~mL}$ and TFC was $11.21 \mathrm{mg}$ CE / $100 \mathrm{~mL}$. The ability of parsley fermented juice to reduce DPPH synthetic radical was $79.45 \%$, while the capacity to reduce $\mathrm{Fe}^{3+}$ was $0.758 \pm 0.14$ (absorbance at $700 \mathrm{~nm}$ ) and to chelate $\mathrm{Fe}^{2+}$ ion was $23.64 \%$. Parsley juice represents an important source of natural nitrate and flavonoids, with important antioxidant capacity.
\end{abstract}

Keywords: Parsley (Petroselinum crispum), vegetable juice, antioxidants, natural nitrate.

\section{INTRODUCTION}

Nitrate is naturally present in soils, water and plants (especially in vegetables) as a consequence of nitrogen fixation. Nitrate is reduced to nitrite by nitrate reductase enzymes. Parsley, among other vegetables, possesses the tendency to accumulate nitrate ${ }^{1}$.
Parsley (Petroselinum crispum) belongs to Apiaceous family and it has been used as food, pharmaceutical, perfume, and cosmetic ingredient ${ }^{2}$. The name petroselinum came from the Greek word "petros" which means "stone" and it is referring to the plant's habit of growing in rocky places ${ }^{1}$. Fejes et al. (2000) investigated phytochemical profile of parsley and revealed the presence of several classes 
of polyphenols, especially flavonoids ${ }^{3}$. The major flavonoids found in parsley are flavonols (kaempferol and quercetin) and glycosylated flavones (apigenin and luteolin). The sanogenous effects of parsley result from the high content in flavonoids (about 100 $\mathrm{mg} / 100 \mathrm{~g}$ fresh weight $\mathrm{t}^{4}$ ) with antioxidant activity and the capacity to scavenge free radicals ${ }^{5}$.

The purpose of this study was to obtain a fermented juice from parsley roots, rich in nitrites and polyphenols, and to test its antioxidant activity (DPPH radical scavenging activity, $\mathrm{Fe}^{3+}$ reducing power activity and $\mathrm{Fe}^{2+}$ chelating activity) comparatively with ascorbic acid solution $(10 \mu \mathrm{g} / \mathrm{mL})$ and butylated hydroxyanisole solution $(10 \mu \mathrm{g} / \mathrm{mL})$.

\section{MATERIALS AND METHODS}

All chemicals and reagents used in the study were of analytical grade and purchased from Sigma chemicals (Romania). Staphylococcus xylosus ATCC 29971 strain used for vegetable juice fermentations was purchased from BioMerieux.

\section{Vegetable juice obtaining}

Parsley roots were bought from a local market and frozen until analyses. Unfrozen plant material was cut into pieces and chopped in a laboratory blender. The fresh juices were sterilized for $15 \mathrm{~min}$ at $121^{\circ} \mathrm{C}$. After sterilization, the juices were filtrated and kept in refrigeration condition, at $4^{\circ} \mathrm{C}$, until analyzes were performed.

\section{Bacterial strains}

Staphylococcus xylosus ATCC 29971, a coagulase-negative and non-toxigenic strain, used for vegetable juice fermentations, was incubated in nutritive broth for 24 hours and then it was used as nitrate reductase source.

\section{Vegetable juice fermentation}

Parsley juice was inoculated with S. xylosus in concentration of $10^{8} \mathrm{CFU} / \mathrm{mL}$ and the fermentation was conducted at $37^{\circ} \mathrm{C}$ for 30 hours.

\section{Determination of nitrate concentration in vegetable juices}

For nitrate determination, it was used a colorimetric method described by Cataldo et al. (1975) $)^{6}$. The complex formed by nitration of salicylic acid under highly acidic conditions absorbs maximally at $410 \mathrm{~nm}$ in alkaline $(\mathrm{pH}>12)$ solutions. The nitrate concentration was determined from 6 to 6 hours for 30 hours, and expressed as $\mathrm{mg}$ nitrate/1000 $\mathrm{mL}(\mathrm{ppm})^{7}$.

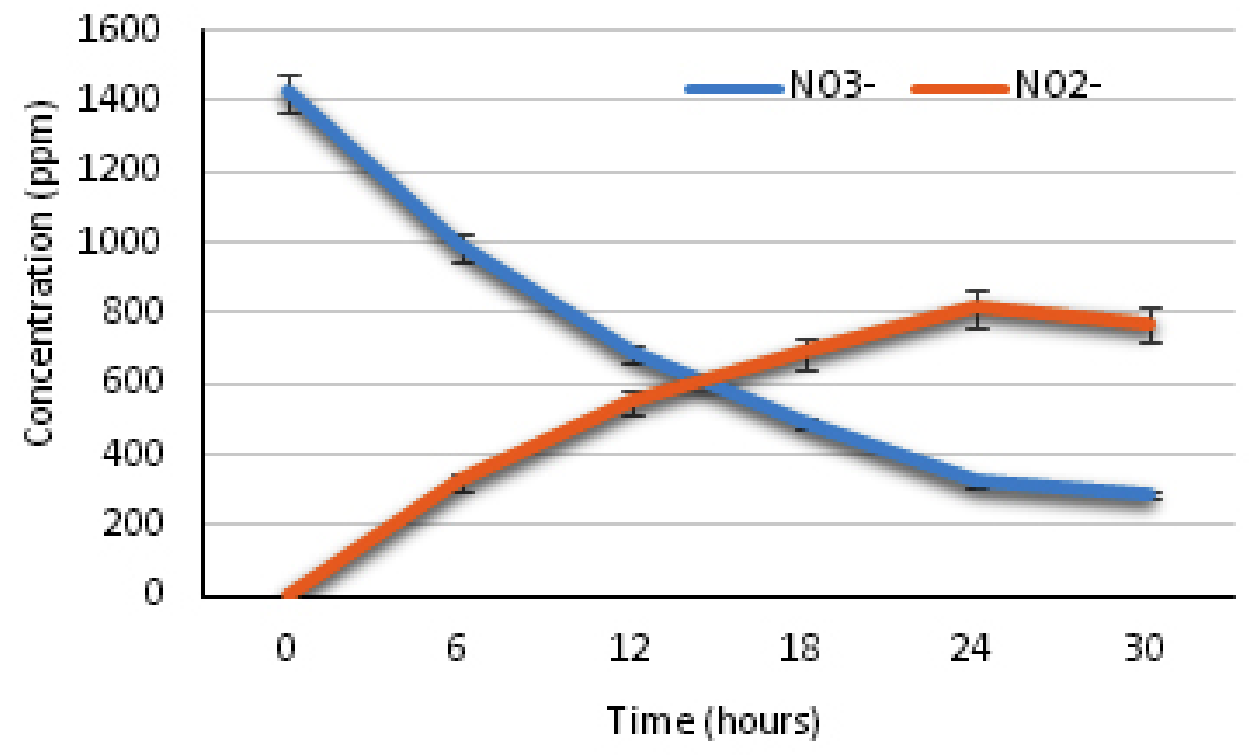

Fig. 1: Nitrates and nitrites concentration in the presence of Staphylococcus xylosus nitrate reductase 


\section{Determination of nitrite concentration in vegetable juices}

Nitrite ions react with Griess reagent and the purple colour that developed after 20 min was read spectrophotometrically at $538 \mathrm{~nm}^{8}$. The nitrite concentration was determined from 6 to 6 hours for 30 hours, and expressed as $\mathrm{mg}$ nitrite/1000 $\mathrm{mL}$ $(\mathrm{ppm})^{7}$.

\section{Determination of total phenolic content (TPC)}

TPC was measured using the FolinCiocalteu colorimetric method ${ }^{9}$. The absorbance of the resulting blue colour was measured at $765 \mathrm{~nm}$. The results were expressed as milligrams of gallic acid equivalents/100 mL juice (mg GAE/100 mL).

\section{Determination of total flavonoid content (TFC)}

The total flavonoid content of fermented juice was determined by the aluminium chloride colorimetric method ${ }^{10}$. The absorbance was measured at $510 \mathrm{~nm}$. The total flavonoid content was calculated from a calibration curve, and the result was expressed as $\mathrm{mg}$ catechin equivalents/100 mL juice (mg CE/100 mL).

\section{Determination of antioxidant activity (AA)}

Antioxidant activity of parsley fermented juices was compared to the one of ascorbic acid (10 $\mu \mathrm{g} / \mathrm{mL})$ and butylated hydroxyanisole $(10 \mu \mathrm{g} / \mathrm{mL})$.

- DPPH radical scavenging activity. The ability of fermented juices to scavenge DPPH synthetic radical was assessed according to the method of Burits and Bucar (2000), with some modifications ${ }^{11}$. Aliquots of $1.95 \mathrm{~mL}$ of $0.2 \mathrm{mM}$ DPPH ethanolic solution were mixed with $50 \mu \mathrm{L}$ of the samples. The mixture was shaken vigorously and then kept at room temperature for $30 \mathrm{~min}$ in the dark. The absorbance was measured at $517 \mathrm{~nm}$. DPPH radical scavenging activity was expressed as $\%$ Inhibition.

- $\quad \mathrm{Fe}^{3+}$ reducing power activity. The reducing power of the fermented juices was determined according to the method of Oyaizu (1986) ${ }^{12}$ $\mathrm{Fe}^{3+}$ reducing power activity was expressed as absorbance at $700 \mathrm{~nm}$ (A700 nm).

- $\quad \mathrm{Fe}^{2+}$ chelating activity. $\mathrm{Fe}^{2+}$ chelating activity was measured according to the method of Benzie and Strain (1996) ${ }^{13}$ and it was expressed as \% Chelation $\left[\%\right.$ Chelation $=\left(A_{c}\right.$
$\left.\left.-A_{s}\right) / A_{c} \times 100\right)$, where $A_{c}$ is the absorbance of the control and $A_{s}$ is the absorbance of the sample].

All determinations were made in triplicate.

\section{RESULTS AND DISCUSSION}

\section{Determination of nitrate and nitrite concentration in vegetable juices}

During the 30 hours of fermentation, the nitrate was reduced to nitrite. The initial concentration of nitrate in parsley juice was $1425.01 \pm 54.94$ ppm. In the presence of the microbial nitrate reductase, the nitrate concentration decreased to $287.19 \pm 14.11$ ppm, after 30 hours of fermentation (Figure 1).

After 6 hours of fermentation, the nitrite concentration was $321.32 \pm 36.46 \mathrm{ppm}$. At the end of fermentation experiment, the nitrite concentration increased up to $767.25 \pm 51.13 \mathrm{ppm}$ (Figure 1). The conversion rate of nitrate to nitrite in the reduction reaction was calculated: after 24 hours of fermentation, the conversion of nitrate to nitrite was $77.01 \%$ and after 30 hours it was $72.56 \%$; after 24 hours of fermentation, a secondary reaction occurred (Table 1).

Determination of total phenolic content (TPC) and total flavonoid content (TFC)

Parsley roots contain high levels of phenolics, some of them soluble in aqueous media. For this reason, in the fermented juice these compounds with antioxidant activity were recovered. Total phenolic content (TPC) and total flavonoid content (TFC) found in fermented parsley juice are presented in Table 2; total flavonoids represent $75.39 \%$ from total phenolic content.

\section{Determination of antioxidant activity}

As expected, due to high content in flavonoids, fermented parsley juice exhibited an important antioxidant activity (Table 3). DPPH scavenging activity of a product depends on the ability of its antioxidant compounds to lose hydrogen and the structural conformation of these components ${ }^{14}$. Parsley fermented juice contains phenolic compounds able to convert the free radical in a stable diamagnetic molecule, which causes discoloration of DPPH solution. DPPH radical scavenging activity, expressed as \% Inhibition, 
Table 1: Nitrate-nitrite conversion rate

(\%) in the presence of Staphylococcus xylosus nitrate reductase

\begin{tabular}{lc}
\hline Time (hours) & Conversion rate (\%) \\
\hline 6 & 30.37 \\
12 & 51.75 \\
18 & 65.18 \\
24 & 77.01 \\
30 & 72.56 \\
\hline
\end{tabular}

Table 2 : The total phenolic content (TPC) and total flavonoid content (TFC) concentration of fermented parsley juice

\begin{tabular}{lcc}
\hline Sample & $\begin{array}{c}\text { TPC } \\
(\mathbf{m g ~ G A E} / 100 \mathrm{~mL})\end{array}$ & $\begin{array}{c}\text { TFC } \\
(\mathbf{m g ~ C E} / \mathbf{1 0 0} \mathbf{~ m L})\end{array}$ \\
\hline Parsley & $14.87 \pm 1.03$ & $11.21 \pm 1.11$ \\
\hline
\end{tabular}

Table 3 : Antioxidant activity of fermented parsley juice compared to ascorbic acid and butylated hydroxyanisole

\begin{tabular}{lccc}
\hline Sample & $\begin{array}{c}\text { DPPH scavenging } \\
\text { activity(\% Inhibition) }\end{array}$ & $\begin{array}{c}\mathbf{F e}^{3+} \text { reducing } \\
\text { power(A 700 } \mathbf{~ m} \text { ) }\end{array}$ & $\begin{array}{c}\mathbf{F e}^{2+} \text { chelating } \\
\text { activity\%Chelation }\end{array}$ \\
\hline Parsley & $79.45 \pm 6.23$ & $0.758 \pm 0.140$ & $23.64 \pm 2.14$ \\
Ascorbic acid $(10 \mu \mathrm{g} / \mathrm{mL})$ & $59.36 \pm 4.25$ & $0.644 \pm 0.071$ & $66.36 \pm 5.47$ \\
Butylated hydroxyanisole & $77.12 \pm 6.47$ & $0.760 \pm 0.078$ & $78.36 \pm 7.14$ \\
$(10 \mu \mathrm{g} / \mathrm{mL})$ & & & \\
\hline
\end{tabular}

found in parsley fermented juice, was $79.45 \pm 6.23$. $\mathrm{Fe}^{3+}$ reducing power activity of a juice containing antioxidants reflects the ability of antioxidants to donate electrons, to be reducer compounds. $\mathrm{Fe}^{3+}$ reducing power activity of the fermented parsley juice, expressed as absorbance at $700 \mathrm{~nm}$, was $0.758 \pm 0.14$, which demonstrates an appreciable antioxidant activity. $\mathrm{Fe}^{2+}$ is pro-oxidant due to its implication in generation of $\mathrm{HO}$. in Fenton reaction. Therefore, the compounds able to chelate this cation are strong antioxidants because they prevent $\mathrm{HO}$. generation in Fenton reaction, which is the most aggressive free radical. $\mathrm{Fe}^{2+}$ chelating activity of fermented parsley juice, expressed as \% Chelation, was $23.64 \pm 2.14$, which indicates the presence of phenolics with hydroxyl groups in the vicinal positions, able to chelate $\mathrm{Fe}^{2+}$.
The results showed that fermented parsley juice represents an important source of natural nitrate. The conversion of nitrate to nitrite was maximum after $24 \mathrm{~h}$ of fermentation. Also, fermented parsley juice contains high level of flavonoids with antioxidant activity. DPPH. scavenging activity and $\mathrm{Fe}^{3+}$ reducing power activity of fermented parsley juice was approximately equal with those found for butylated hydroxyanisole solution and slightly higher than those found for ascorbic acid. $\mathrm{Fe}^{2+}$ chelating activity found for parsley fermented juice was much lower than the values found for standard solutions.

\section{ACKNOWLEDGEMENTS}

This work was carried out through Partnerships in priority areas Program - PN II, implemented with the support of MEN - UEFISCDI (Romania), project nr. 149/2014.

\section{REFERENCES}

1. Mor F, Sahindokuyucu F, Erdogan N. Nitrate and Nitrite Contents of Some Vegetables Consumed in South Province of Turkey. Journal of Animal and Veterinary Advances;
9: 2013-2016: (2010).

2. Lopez M. G, Sanchez-Mendoza I. R, OchoaAlejo N. Comparative Study of Volatile Components and Fatty Acids of Plants and in- 
vitro Cultures of Parsley Petroselinum crispum (Mill) nym ex hill. Journal of Agricultural and Food Chemistry; 47: 3292-3296: (1999).

3. Fejes S. Z, Blazovics A, Lemberkovics E, Petri G, Szoke E, Kery A. Free Radical Scavenging and Membrane Protective Effects of Methanol Extracts from Anthriscus cerefolium (Hoffm) L. and Petroselinum crispum (Mill) Nym. Ex A. W. Hill. Phytotherapy Research; 14: 362-365: (2000).

4. Hall I. H, Scoville J. P, Reynolds D. J, Simlot R, Duncan P. Substituted Cyclic Imides as Potential Anti-Gout Agents. Life Sciences; 46: 1923-1927: (1990).

5. Potapovich A. I, Kostyuk V. A. Comparative Study of Antioxidant Properties and Cytoprotective Activity of Flavonoids. Biochemistry; 68: 514-519: (2003).

6. Cataldo D. A, Haroon L. E, Schrader L. E, Youngs V. L. Rapid Colorimetric Determination of Nitrate in Plant Tissue by Nitration of Salicylic Acid. Communications in Soil Science and Plant Analysis; 6: 71-80: (1975).

7. Predescu N. C, Papuc C, Nicorescu V, Dobrea M. Optimization of Fermentation Parameters for Vegetable Juices with Nitrate Content to Obtain Natural Nitrites. Lucrari Stiintifice USAMV Ion Ionescu de la Brad lasi Seria Medicina Veterinara; 58(17)-I: 76-82: (2015).

8. Giustarini D, Rossi R, Milzani A, Dalle-Donne I. Nitrite and Nitrate Measurement by Griess Reagent in Human Plasma: Evaluation of
Interferences and Standardization. Methods in Enzymology; 440: 361-380: (2008).

9. Singleton V. L, Rosi J. A. Colorimetric of Total Phenolics with PhosphomolybdicPhosphotungstic Acid Reagents. American Journal of Enology and Viticulture; 16: 144158: (1965).

10. Chang $\mathrm{C}$, Yang M, Wen H, Chern J. Estimation of Total Flavonoid Content in Propolis by Two Complementary Colorimetric Methods. Journal of Food and Drug Analysis; 10: 178182: (2002).

11. Burits M, Bucar F. Antioxidant Activity of Nigella sativa Essential Oil. Phytotherapy Research; 14(5): 323-328: (2000).

12. Oyaizu M. Studies on Products of Browning Reaction: Antioxidative Activity of Products of Browning Reaction Prepared from Glucosamine. Japanese Journal of Nutrition; 44: 307-315: (1986).

13. Benzie I. F. F, Strain J. J. The Ferric Reducing Ability of Plasma (FRAP) as a Measure of "Antioxidant Power": the FRAP Assay. Analytical Biochemistry; 239(1): 70-76: (1996).

14. Aksoy L, Kolay E, Aðýlönü Y, Aslan Z, Kargýoðlu M. Free Radical Scavenging Activity, Total Phenolic Content, Total Antioxidant Status, and Total Oxidant Status of Endemic Thermopsis turcica. Saudi Journal of Biological Sciences; 20(3): 235239: (2013). 